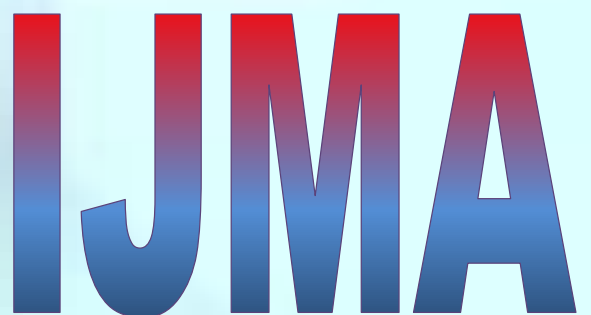

INTERNATIONAL

Journal of MEdical

\section{ARTS}

Volume 3, Issue 1 (Winter 2021)

http://ijma.journals.ekb.eg/

Print ISSN: 2636-4174

Online ISSN: 2682-3780

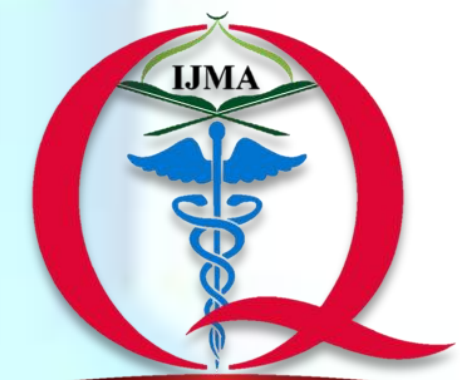

International Jounnal of Medical Arts

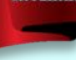




\section{About IJMA}

- International Journal of Medical Arts is the Official Journal of the Damietta Faculty of Medicine, Al-Azhar University, Egypt

- The First Issue was published in July 2019

- It is an International, Open Access, Double-blind, Peerreviewed Journal

- Published four times a year

- Published under the following license: Creative Commons Attribution-ShareAlike 4.0 International Public License (CC BY-SA 4.0). It had updated from the Creative Commons license [CC BY] in volume 2, Issue 4, October 2020

- The Egyptian Knowledge Bank hosts the web site of IJMA

- The Egyptian Knowledge Bank supports IJMA

- IJMA is indexed in the "Directory of Open Access Journals" Indexed on 15 January 2021.

- IJMA follows the regulations of the International Committee of Medical Journal Editors (list date 1/21/20)

- IJMA is a member of The International Society of Managing and Technical Editors

- IJMA is listed in Index Copernicus

- IJMA is listed in Publons, as EKB is an official partner with Clarivate Analytics
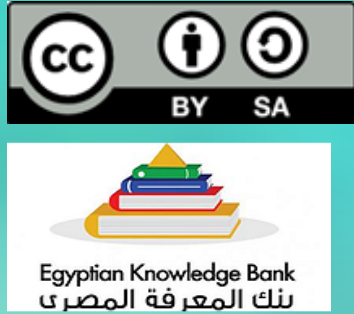

\section{DOAJ}

CMNE

ISMTE

INDEX COPERNICUS

publons 
International Journal of Medical Arts 2021; 3 [1]: 1136-1144.

Available online at Journal Website
https://ijma.journals.ekb.eg/
Main subject [Basic Science, Toxicology] ${ }^{*}$

Original article

\title{
Protective Effect of Cinnamon and Ginger on Acrylamide Induced Hepatotoxicity in Adult Male Albino Rats
}

\author{
El-sayed Hamdey El-sayed Gawesh [1]; Ahmed Ibrahim Abdelreheem Elshoura[1]; Mohamed Ali Abbas ${ }^{[2]}$
}

Department of Forensic Medicine and Clinical Toxicology, Damietta Faculty of Medicine, Al-Azhar University, Egypt ${ }^{[1]}$

Department of Medical Physiology, Damietta Faculty of Medicine, Al-Azhar University, Egypt ${ }^{[2]}$

Corresponding author: Mohamed Hamed Alahmer

Email: drmohamedali122@gmail.com

Received at: September 21, 2020; Revised at: December 12, 2020; Accepted at: December 19, 2020

DOI: 10.21608/ijma.2020.43688.1177

\section{ABSTRACT}

Background: Background: Acrylamide $[A C R]$ is an essential chemical that is extensively used in many industries and also in laboratories such as treatment of drinking water, wastewater, and soil, production of paper, petroleum, mine, asphalt, dyes, adhesives, and polishes; it is known as a possible carcinogenic compound. Ginger oleoresin's hepatoprotective role can be attributed to its free radical scavenging, anti-inflammatory, and hypolipidemic activities and is partially mediated by the 6-gingerol, shogaol, and zingerone of its active component. Cinnamomum zeylanicum is used to treat many diseases and to prevent such diseases.

Aim of the work: Evaluation of the effects of cinnamon and ginger extracts administration on Hepatotoxicity adult male albino rats.

Materials and Methods: The groups were divided into five adult male albino rats of a local strain: Group I: acted as a control group with regular salines, group II: hepatotoxicity caused by acrylamid, groups III: hepatotoxicity plus cinnamon, group IV: hepatotoxicity plus ginger, group V: hepatotoxicity plus cinnamon and ginger. Samples for alanine aminotransferase $[A L T]$, aspartate transfers of amino [AST], urea, creatinine, blood urea nitrogen (BUN), total cholesterol, triglyceride [TG], malondialdehyde, tumor necrosis factor a [TNF], superoxide dismutase [SOD], glutathione peroxidase [GPX], as well as total antioxidant [TAC] levels were obtained at the end of the experimental period.

Results: Administration of cinnamon and ginger to hepatotoxic rats led to a significant decrease in the mean value of ALT, AST, urea, creatinine, BUN, MDA, and TNF. In addition, it is associated with a significant increase of SOD, GPX, and TAC.

Conclusion: Cinnamon and ginger have a protective effect against abnormalities in hepatotoxic rats due to its several protective properties.

Keywords: Chronic Rhinosinusitis; Eustachian tube dysfunction; Balloon dilatation; Function endoscopic sinus surgery; Eustachian Tube Dysfunction Questionnaire.

This is an open-access article registered under the Creative Commons, ShareAlike 4.0 International license [CC BY-SA 4.0] [https://creativecommons.org/licenses/by-sa/4.0/legalcode.

\footnotetext{
Please cite this article: Gawesh EHE, Elshoura AIA, Abbas MA. Protective Effect of Cinnamon and Ginger on Acrylamide Induced Hepatotoxicity in Adult Male Albino Rats. IJMA 2021; 3[1]: 1136-1144. DOI: 10.21608/ijma.2020.43688.1177

${ }^{*}$ Main subject and any subcategories have been classified according to the research topic.
} 


\section{INTRODUCTION}

The liver is a major body detoxifying organ. It plays an important role in controlling most concentrations of metabolites, particularly serum ASTs and ALTs, which are used in the diagnosis of liver disease as sensitive biomarkers [1]

Acrylamide [ACR] is a hydrophilic molecule that's very small. In other words, passive diffusion conveniently takes it across the body. Oxidative stress, genotoxicity, neurotoxicity, cancer, developmental disorders, and reproductive toxicity have been shown to trigger [2]. The vinyl monomer of acrylamide is water-soluble and has a range of chemical and industrial uses, e.g., wastewater management or treatment. It is present in a high concentration in potatoes, rice, carrots, Chinese cabbage, lettuce, parsley, onions, spinach, and sugar and olives [3].

Ginger [Zingiber officinale] of the Zingiberaceae family is generally recognized as a medicinal herb as anti-inflammatory, antioxidant, antimicrobial, antiviral and antifungal, cardioprotective, anticancer, and chemopreventive. Gingerol and shogaol are the main ginger-derived components that display lipid peroxidation and metabolic changes. For obese women, weight loss and insulin, leptin resistance, and glucose decreases were promoted[4]. Oleoresin Ginger is dark golden brown viscous oil. It consists of essential oils, organic soluble resins, and other non-volatile pungent components, which comprised homologous series of phenolic ketones. 6-gingerol was effective in preventing hepatic and renal damage by reducing oxidative stress. 6-Gingerol-rich fraction lowers total bilirubin and further restores alanine aminotransferase [ALT], aspartate aminotransferase [AST], alkaline phosphatase [ALP], and gamma glutaryl transpeptidase [GGT] enzymes that sensitive indicators of hepatocellular damage and dysfunction [5].

Cinnamon, an everlasting tropical herb, belongs to the family of Lauraceae. It consists mainly of essential oils, cinnamic acid, cinnamaldehyde and cinnamate, and others. In order to use them in the prevention and treatment of different diseases, the beneficial medicinal properties of cinnamon are measured. These characteristics can be applied to treat some inflammatory conditions thanks to vast therapeutic strategies such as antioxidant, antiinflammatory, antidiabetic, anticancer, cardiovascular, and lipid-lowering properties for cinnamon. By eliminating oxidative stress, cinnamon reduces organ harm[6].

\section{AIM OF THE WORK}

The purpose of this research was to evaluate the impact on acrylamide-induced hepatotoxicity of cinnamon and ginger in adult male albino rats.

\section{MATERIALS AND METHODS}

Animals and experimental design: Fifty adult male local strain albino rats were brought from the center of the Nile, Mansura, Egypt, and selected to be the current research model. All of the rats were around the same age and healthy, ranging in weight from 140 to $160 \mathrm{~g}$ [150 g average weight]. At room temperature and good ventilation, they were housed in stainless steel cages $[25 \times 35 \times 25 \mathrm{~cm}$ for every five rats], and they also earned diet water and commissural rat chow. They were left in the laboratory room for 14 days before the beginning of the acclimatization experiment. Rats were split into equal groups of 5 as follows;

The control group (Group I): Rats fed on normal rat chow diet for four weeks.

Hepatotoxic group (Group II): Rats received oral administration of acrylamide at a dose of 50 $\mathrm{mg} / \mathrm{kg}$ body weight for four weeks[7].

Hepatotoxic plus Cinnamon group (Group III): Rats received oral administration of acrylamide at a dose of $50 \mathrm{mg} / \mathrm{kg}$ body weight for four weeks after the $4^{\text {th }}$ week, rats received $400 \mathrm{mg} / \mathrm{kg}$ cinnamon extract by oral gavage daily for five weeks[8].

Hepatotoxic plus ginger group (Group IV): Rats received oral administration of acrylamide at a dose of $50 \mathrm{mg} / \mathrm{kg}$ body weight for four weeks. After the $4^{\text {th }}$ week, rats received $400 \mathrm{mg} / \mathrm{kg}$ ginger extract by oral gavage daily for five weeks ${ }^{[9]}$.

Group V [hepatotoxic plus cinnamon and ginger group]: Rats received oral administration of acrylamide at a dose of $50 \mathrm{mg} / \mathrm{kg}$ body weight for four weeks. After the $4^{\text {th }}$ week, rats received cinnamon and ginger extracts by oral gavage daily for five weeks 
Induction of hepatotoxicity: Pure [99\%] acrylamide was brought from Sigma Chemical Company [Egypt, Eltayaran st., Nasr city-Cairo]. Acrylamide [50 mg/kg/day] was dissolved in $10 \mathrm{ml}$ distilled water, so each $1 \mathrm{ml}$ distilled water contained $5 \mathrm{ml}$ acrylamide. Each rat was given distilled water containing acrylamide by weight and orally administered to rats for four weeks via gastric intubation[7].

Cinnamon extract preparation: Cinnamon powder was obtained in New Damietta from a local market. $10 \mathrm{~g}$ were then weighed and mixed with 100 $\mathrm{ml}$ of water and held for two hours in a water bath at $60^{\circ} \mathrm{C}$, then filtered by $150 \mu$ Capron silica fabric. These diluted extracts [water 1:10] were administered by a feeding needle [oral gavage] to rats. The philtre was kept in the dark bottles at $\left[4^{\circ} \mathrm{C}\right]$ in the refrigerator. Such procedures are replicated every week[10].

Ginger extract preparation: Ginger powder was purchased from a local market in New Damietta. Then $10 \mathrm{~g}$ was soaked for 6 hours in 100 $\mathrm{ml}$ [10 percent] hot water [88 C] in a water bath. Then $150 \mu$ of Capron silica cloth is filtered. These diluted extracts [water 1:10] were administered by a feeding needle [oral gavage] to rats. The philtre was kept in the dark bottles at $\left[4^{\circ} \mathrm{C}\right]$ in the refrigerator. Such procedures are replicated every week [11].

Ethyl Ether [Analar, Nile Pharmaceutical]: For anesthesia

Collection of Blood and tissue: All rats were fasted overnight at the end of the experimental duration and anesthetized by putting them in an anesthetic box filled with ether vapor. Ether vapor was preserved by adding liquid ether to the cotton wool at the box's base periodically. Using the heparinized capillary tube, blood was extracted from the retro-orbital plexus, left to clot to acquire serum, and centrifuged for 10 minutes at a rate of 5000 per minute. Serum in Eppendorf tubes was sucked out and deposited frozen at $-20^{\circ} \mathrm{C}[12]$. Aspartate aminotransferase [AST], alanine aminotransferase $[A L T]^{[13]}$, urea ${ }^{[14]}$, creatinine ${ }^{[15]}$, blood urea nitrogen $[\mathrm{BUN}]{ }^{[16]}$, total cholesterol[17], TG[18], malondialdehyde ${ }^{[19]}$, tumor necrosis factor- $\alpha$ [TNFa] ${ }^{[20]}$, superoxide dismutase [SOD] [21], glutathione peroxidase [GPX] ${ }^{[22]}$ and total antioxidant capacity [TAC] ${ }^{[23]}$ were assayed.
Statistical analysis: The data's input and analysis was performed using the computer program Statistical Package for Social Sciences [SPSS] version 19. All outcomes were expressed as mean \pm standard deviation. The mean values of the various groups were compared using one-way variance analysis or student t-tests. A post hoc analysis of the least significant difference [LSD] was used to identify significantly different mean values. To denote a significant difference, a $p$-value $<0.05$ was accepted.

\section{RESULTS}

Results of the current study showed that oral administration of acrylamide at a dose of $50 \mathrm{mg} / \mathrm{kg}$ body weight for four weeks resulted in a statistically significant increase in ALT, AST, urea, creatinine, BUN, MDA, TNF associated with a significant decrease in SOD, GPX, and TAC, as well as an insignificant increase in TC and TG in Group II compared to Group I [Table 1]. Cinnamon administration to hepatotoxic rats resulted in a significant decrease in mean ALT, AST, urea, creatinine, BUN, MDA, TNF values associated with a significant increase in SOD, GPX, and TAC, in addition to an insignificant decrease in TC and TG levels in group III compared to group II. Ginger administration to hepatotoxic rats also resulted in a significant reduction in mean ALT, AST, urea, creatinine, BUN, MDA, TNF values associated with a significant increase in SOD, GPX, and TAC, in addition to an insignificant decrease in TC and TG levels in group III compared to group III [Table 2]. Administration of cinnamon plus ginger to hepatotoxic rats led to a significant decrease in the mean value of $A L T, A S T$, urea, creatinine, BUN, MDA, TNF associated with a significant increase of SOD, GPX, and TAC, in addition to the insignificant decrease of TC and TG in group III when compared with group II [Table 2].

In the present study, when group IV compare with group III, there were insignificant changes between all parameters. In addition to when group V compared with group III and with group IV, there was a significant decrease in the mean value of ALT, AST, urea, creatinine, BUN, MDA, TNF associated with the significant increase of SOD, GPX, and TAC, in addition to the insignificant decrease of TC and TG [Table 3]. 
Table [1]: Comparison between group I and II [Mean \pm SD].

\begin{tabular}{|l|c|c|c|c|}
\hline & Group I & Group II & t-test & P-value \\
\cline { 2 - 3 } & Mean \pm SD & Mean \pm SD & & \\
\hline ALT [U/L] & $33.39 \pm 1.7$ & $53.82 \pm 2.3$ & 22.52 & $<0.001^{*}$ \\
\hline AST [U/L] & $29.3 \pm 0.84$ & $48.46 \pm 1.44$ & 36.36 & $<0.001^{*}$ \\
\hline Urea [mg/dl] & $22.42 \pm 1.86$ & $34.15 \pm 3.14$ & 10.16 & $<0.001^{*}$ \\
\hline Creatinin [mg/dl] & $0.55 \pm 0.18$ & $2.01 \pm 0.27$ & 14.03 & $<0.001^{*}$ \\
\hline BUN [mg/dl] & $7.3 \pm 0.55$ & $14.7 \pm 0.71$ & 25.98 & $<0.001^{*}$ \\
\hline TC [mg/dl] & $111.1 \pm 4.25$ & $118.7 \pm 10.57$ & 2.11 & 0.06 \\
\hline TG [mg/dl] & $103.4 \pm 7.5$ & $107.4 \pm 3.27$ & 1.55 & 0.14 \\
\hline MDA [nmol/L] & $17.1 \pm 1.52$ & $30.7 \pm 4.11$ & 9.81 & $<0.001^{*}$ \\
\hline TNF [pg/ml] & $57.3 \pm 5.48$ & $94.3 \pm 5.17$ & 15.54 & $<0.001^{*}$ \\
\hline SOD [mg/dl] & $72.0 \pm 4.27$ & $52.4 \pm 4.29$ & 10.23 & $<0.001^{*}$ \\
\hline GPX [mg/dl] & $23.6 \pm 1.78$ & $15.2 \pm 2.15$ & 9.52 & $<0.001^{*}$ \\
\hline TAC [nmol/L] & $9.26 \pm 0.47$ & $7.15 \pm 0.29$ & 11.93 & $<0.001^{*}$ \\
\hline
\end{tabular}

= Significant difference between the two groups; Group I: Control group; Group II: Hepatotoxic group; SD = Standard deviation.

Table [2]: Effects of cinnamon and ginger on the hepatotoxic group [Mean \pm SD].

\begin{tabular}{|l|c|c|c|c|}
\hline \multicolumn{1}{|c|}{ Groups } & Group II & Group III & Group IV & Group V \\
\hline ALT [U/L] & $53.82 \pm 2.3$ & $47.94 \pm 1.5^{*}$ & $46.57 \pm 1.95^{*}$ & $41.2 \pm 1.63^{*}$ \\
\hline AST [U/L] & $48.46 \pm 1.44$ & $43.38 \pm 3.8^{*}$ & $41.79 \pm 3.72^{*}$ & $36.3 \pm 2.25^{*}$ \\
\hline Urea [mg/dl] & $34.15 \pm 3.14$ & $29.0 \pm 1.26^{*}$ & $29.54 \pm 0.98^{*}$ & $27.8 \pm 1.15^{*}$ \\
\hline Creatinin [mg/dl] & $2.01 \pm 0.27$ & $1.63 \pm 0.16^{*}$ & $1.48 \pm 0.17^{*}$ & $1.25 \pm 0.14^{*}$ \\
\hline BUN [mg/dl] & $14.7 \pm 0.71$ & $12.63 \pm 0.47^{*}$ & $12.3 \pm 0.49^{*}$ & $10.53 \pm 0.33^{*}$ \\
\hline TC [mg/dl] & $118.7 \pm 10.57$ & $113.0 \pm 5.87$ & $111.9 \pm 7.46$ & $111.7 \pm 5.14$ \\
\hline TG [mg/dl] & $107.4 \pm 3.27$ & $105.9 \pm 2.33$ & $104.9 \pm 3.07$ & $104.8 \pm 2.7$ \\
\hline MDA [nmol/L] & $30.7 \pm 4.11$ & $24.4 \pm 1.89^{*}$ & $22.5 \pm 2.17^{*}$ & $20.5 \pm 1.43^{*}$ \\
\hline TNF [pg/ml] & $94.3 \pm 5.17$ & $84.8 \pm 3.35^{*}$ & $81.3 \pm 4.55^{*}$ & $62.8 \pm 4.42^{*}$ \\
\hline SOD [mg/dl] & $52.4 \pm 4.29$ & $57.0 \pm 2.75^{*}$ & $59.3 \pm 2.71^{*}$ & $63.9 \pm 3.07^{*}$ \\
\hline GPX [mg/dl] & $15.2 \pm 2.15$ & $17.6 \pm 1.07^{*}$ & $18.2 \pm 1.14^{*}$ & $20.14 \pm 1.01^{*}$ \\
\hline TAC [nmol/L] & $7.15 \pm 0.29$ & $8.4 \pm 0.32^{*}$ & $8.49 \pm 0.35^{*}$ & $9.14 \pm 0.18^{*}$ \\
\hline
\end{tabular}

${ }^{*}$ = Significant difference compared to group II; Group II: Hepatotoxic group; Group III: Hepatotoxic plus cinnamon group; Group IV: Hepatotoxic plus ginger group; Group V: hepatotoxic plus cinnamon and ginger group

Table [3]: Comparison between groups III, IV and V [Mean \pm SD].

\begin{tabular}{|c|c|c|c|}
\hline $\begin{array}{l}\text { Groups } \\
\text { Parameters }\end{array}$ & Group III & Group IV & Group V \\
\hline ALT [U/L] & $47.94 \pm 1.5$ & $46.57 \pm 1.95$ & $41.2 \pm 1.63^{*} \#$ \\
\hline AST [U/L] & $43.38 \pm 3.8$ & $41.79 \pm 3.72$ & $36.3 \pm 2.25^{*} \#$ \\
\hline Urea [mg/dl] & $29.0 \pm 1.26$ & $29.54 \pm 0.98$ & $27.8 \pm 1.15^{\star} \#$ \\
\hline Creatinin [mg/dl] & $1.63 \pm 0.16$ & $1.48 \pm 0.17$ & $1.25 \pm 0.14^{*} \#$ \\
\hline BUN [mg/dl] & $12.63 \pm 0.47$ & $12.3 \pm 0.49$ & $10.53 \pm 0.33^{*} \#$ \\
\hline $\mathrm{TC}[\mathrm{mg} / \mathrm{dl}]$ & $113.0 \pm 5.87$ & $111.9 \pm 7.46$ & $111.7 \pm 5.14$ \\
\hline TG [mg/dl] & $105.9 \pm 2.33$ & $104.9 \pm 3.07$ & $104.8 \pm 2.7$ \\
\hline MDA [nmol/L] & $24.4 \pm 1.89$ & $22.5 \pm 2.17$ & $20.5 \pm 1.43^{\star} \#$ \\
\hline TNF [pg/ml] & $84.8 \pm 3.35$ & $81.3 \pm 4.55$ & $62.8 \pm 4.42^{*} \#$ \\
\hline SOD [mg/dl] & $57.0 \pm 2.75$ & $59.3 \pm 2.71$ & $63.9 \pm 3.07^{\star} \#$ \\
\hline GPX [mg/dl] & $17.6 \pm 1.07$ & $18.2 \pm 1.14$ & $20.14 \pm 1.01^{*} \#$ \\
\hline TAC [nmol/L] & $8.4 \pm 0.32$ & $8.49 \pm 0.35$ & $9.14 \pm 0.18^{*} \#$ \\
\hline
\end{tabular}

* = Significant difference compared to group III; \# = Significant difference compared to group IV; Group III: Hepatotoxic plus cinnamon group; Group IV: Hepatotoxic plus ginger group; Group V: hepatotoxic plus cinnamon and ginger group

\section{DISCUSSION}

This study was designed to evaluate cinnamon's effect and ginger on hepatotoxicity induced by acrylamide in adult male albino rats. Results of the present study showed that oral administration of acrylamide [AA] at a dose of $50 \mathrm{mg} / \mathrm{kg}$ body weight for four weeks resulted in a statistically significant increase in ALT, AST, urea, creatinine, BUN, MDA, TNF-a, associated with a significant decrease of 
SOD, GPX, and TAC in group II compared to group I. Elhelaly et al. [24] asserted that oral administration of acrylamide, due to severe damage to the tissue membranes, resulted in significantly increased levels of ALT and AST. The viability of hepatic tissue was impaired by acrylamide, damaging its architecture through the loss of phenotypic features. In hepatic tissue, it produced an acute timedependent toxic response[25].

Acrylamide produced free radicals, which can cause liver damage. Free radicals have already been reported to be more reactive than molecular elements and cause serious harm to nucleic acids, proteins, and cell membranes [26].

These results also agreed with Hamdy et al.[27] and Belhadj Benziane et al.[28], who reported that blood urea, creatinine, and BUN levels increased after acrylamide administration.

Urea is filtered by the renal glomerulus from plasma. Via renal tubules, it returns to the blood, but much of it is excreted via urine. However, if the kidney does not function correctly, plasma does not expel adequate urea, leading to higher BUN levels. To show the origin of the renal form, BUN should be considered along with serum creatinine ${ }^{[29]}$.

The present study compatible with Elhelaly et al.[24], who indicated that acrylamide oral administration led to significantly increased TNF and MDA levels. In addition to a significant decreased in GPX and SOD.

Abdel-Daim et al.[30] reported that acrylamide has dangerous effects on liver and kidney tissues due to it raises the incidence of lipid peroxidation and changes antioxidant enzyme systems. Such a drastic increase in the incidence of lipid peroxidation, especially in the liver and kidneys, has a potential role to play in altering the state of an organism's oxidative stress and has seen a decrease in the concentration of GSP and SOD.

Acrylamide resulted in excessive levels of reactive oxygen species [ROS]. It can reduce the level of antioxidant protection in the organ, resulting in an imbalance between the production and removal of free radicals by antioxidant defense ${ }^{[31]}$.
The present study showed insignificant increased TC and TG and these similar to Akram et al.[32], who reported that low doses of acrylamide cause significant increases in total cholesterol and triglyceride levels compared with controls due to lipid peroxidation, the liver has a vital role in the synthesis of whole-body lipids and the metabolism of carbohydrates[25].

The present work resulted in substantial decreases in the mean value of ALT and AST, in addition to a small reduction of TC and TG, for cinnamon and ginger or both to hepatotoxic rats. These findings are consistent with Ismail et al. [33] that indicated the substantial decrease in AST, ALT, cholesterol, and triglyceride in cinnamon administration to hepatotoxic rats. Shalaby and Saifann ${ }^{[34]}$ found that in diabetic obese rats, cinnamon aqueous extract developed hypo-lipidemic, diabetic, hepatoprotective, and anti-oxidant effects.

The hepatoprotective effect of cinnamon extract through stimulation of liver synthesis of protein helps speed up recovery and the development of the liver cells $s^{[35]}$. It helps to regenerate the injured liver cells by stimulating the enzyme RNA polymerase I, which increases the synthesis of ribosomal proteins and helps regenerate hepatocytes[36].

Dietary cinnamon inhibits the hepatic activity of hydroxy-3-methylglutaryl-coenzyme A [HMG Co-A] reductase, which decreases lipids and improves lipid peroxidation by enhancing the function of the lipid antioxidant enzyme [35]. The development of LDL-R gene expression is also a mechanism for lowering the lipid activity of cinnamon [37]. Cinnamon did not alter the rats' lipid profile in the proportion of the human diet, but it increased the lipolysis of the fatty tissue of the dietary mouse ${ }^{[38]}$.

Ginger enhances lipid profile because of ginger's pharmacological effects that enhance the hepatic cholesterol activity -7a-hydroxylase, which is the rate-limiting enzyme for bile acid biosynthesis and stimulation cholesterol conversion into bile acids ${ }^{[39]}$. In addition, ginger antihypercholesterol may be caused by cellular cholesterol inhibition because of niacin, lower TG levels, hepatic 
absorbance of LDL, and cholesterogenesis inhibition. Ginger antioxidants can prevent membranous lipid peroxidation leading to cell damage and necrosis [40].

The ginger components demonstrated significant inhibition of the mediated cytochrome P450 metabolism of marker substrates and blocked the cytochrome P450-2E1 enzyme to prevent bromobenzene-induced hepatotoxicity[41].

This also led to a consensus with Shatwan et al.[42], who noted that the high levels of TC and TG in men and rats are decreased by cinnamon and ginger. Due to their large polyphenols [cinnamon], gingerols, and shogaols [ginger] that inhibit intestinal absorption by hypocholesterol activity, the probable potential mechanism underlies its hypolipidemic effects may also have a high content of polyphenols.

The present paper shows a substantial decrease in the mean urea, creatinine, and BUN value when administering cinnamon and ginger or both to hepatotoxic rats. These findings were consistent with Ismail et al.[33], which recorded substantial decreases of urea and creatinine in cinnamon administration to hepato-intoxicated rats. Mani et al. [43] indicated that Ginger's administration resulted in a major reduction in urea, creatinine, and BUN, which is consistent with our findings because Zingerone maintains the kidneys' toxicity functional capability. Shanmugam et al.[44] indicated that ginger extracts' supplementation prevented large renal tubules and changes in renal tissue degenerative.

In the present work, cinnamon and ginger administration or both to hepatotoxic rats led to a significant decrease in the mean value of MDA, TNF associated with a significant increase of SOD, GPX, and TAC. These results are in-agreement with Qin et al. [45], who asserted that cinnamon extract supplementation reduced tumor necrosis factor- $a$ and MDA. Gholamreza et al.[46] assured that cinnamon administration led to a significant decrease of MDA and TNF associated with increased TAC and SOD due to high phenol contents and excellent potential in scavenging free radicals.

Cinnamon extract existed in liposomes and tapering hydroxyl radicals [OH॰] and $\mathrm{H}_{2} \mathrm{O}_{2}$ for protective capacities against radiation-induced lipid peroxidation phase [LPO]. Cinnamon's protective effect on ROS development is due to its suppressive effect against irradiation-induced oxidative and inflammatory harm. Apart from altering gene expression by inhibiting nuclear factor kappa B [NF-Kb] activation, this is due to its phenolic and flavonoid content. Polyphenols serve as scavengers for reactive oxygen and nitrogen, transitional redox metal chelators, and modulators for the enzyme ${ }^{[47]}$.

Administration of liver damage to the Cinnamon Oils led to a substantial increase of hepatic GSP and SOD by lipid peroxidation suppression and protein oxidation, ROS development inhibition in conjunction with radical activity, and decreased DNA carcinogenic interaction showing the restoration of the liver's antioxidant system [48].

Ginger extract can reduce the elevated expression of TNF-a in rats. Ginger significantly inhibits serum TNF alpha levels. Since the inflammatory response is an inducer of reactive oxygen species [ROS] generation. Ginger has the spectrum of activity as an anti-inflammatory and antioxidant agent ${ }^{[49]}$.

Zhang et al.[50] noticed a substantial increase in total SOD, TAC, and GPX by dietary supplementation with ginger powder but reported a decrease in the MDA level. These findings relate to the results of our study.

Malondialdehyde is formed as an end product of lipid peroxidation, and so, the extent of lipid peroxidation by ROS can be determined according to MDA levels. The decrease in MDA and TAC increase indicates decreased oxidative stress or an increase in total antioxidant defense. Accordingly, reduction in MDA level in treatments containing cinnamon and ginger compared to control proved that lipid peroxidation was reduced by consuming medical plants and increasing the antioxidative activities. Besides, a decrease in the concentration 
of MDA in serum can be related to an increase in antioxidant enzyme activity because of the use of medicinal herbal supplements [51].

Conclusion: Administration of Cinnamon and ginger to liver toxicity led to a significant decrease in liver enzymes and considerable improvement of oxidative stress that led to many diseases.

Financial and Non-financial Relationships and Activities of Interest

None

\section{REFERENCES}

1-Alwan N, Alkalby J, Al-Masoudi E. Effect of acrylamide on thyroid and liver functions in adult male rats. Indo- Asian J Multidisciplin Res. 2016; 2(4):673-680. doi: 10. 21276.iajmr.2016.2.4.4.

2-Mahmood S, Amin K, Rahman H, Othman H. The Pathophysiological Effects of Acrylamide in Albino Wister Rats. Int J Med Res\& Health Sci. 2016, 7:42-48. Available at: http://www.indianjournals.com/ijor. aspx? target=ijor:ijmrhs\&volume $=5$ \&issue $=7$ \&article $=007$

3-Moawad RS, Abd El Fattah ER, Ramadan RS. Postnatal Effect of Acrylamide on Rat Renal Cortex and the Protective Effect of Ginger (Zingiber Officinale Roscoe). Egypt J Histol. 2018; 42(1): 51-63. doi: 10.21608/ ejh. 2018.4135.1012

4-Leal DT, Fontes GG, Villa JK, Freitas RB, Campos MG, Carvalho CA, Pizziolo VR, Diaz MA. Zingiber officinale formulation reduces hepatic injury and weight gain in rats fed an unhealthy diet. Anais da Academia Brasileira de Ciências, 2019; 91(4): 20180975. doi: 10.1590/00013765201920180975 .

5-Salihu M, Ajayi BO, Adedara IA, de Souza D, Rocha JB, Farombi EO. 6-Gingerol-Rich Fraction From Zingiber Officinale Prevents Hematotoxicity and Oxidative Damage in Kidney and Liver of Rats Exposed to Carbendazim. J Diet Suppl., 2016; 13(4): 433-48. doi: 10.3109/19390211.2015.1107802.

6-Mahmoud H, Oliaee RT, Kareshk AT, Mirbadie SR, Aflatoonian MR. In vitro protoscolicidal effects of Cinnamomum zeylanicum essential oil and its toxicity in mice. Pharmacogn Mag. 2017; 13 (2017): 652-657 doi.org/10.4103/pm.pm_280_16.

7-Sun R, Chen W, Cao X, Guo J, Wang J. Protective Effect of Curcumin on Acrylamide-Induced Hepatic and Renal Impairment in Rats: Involvement of CYP2E1. Nat Product Commun. 2020; 15(3): 1-9 doi: 10.1177/ 1934578X20910548].
8-Elkomy A, Aboubakr M, Soliman A, Abdeen A, Abdelkader A, Hekal $H$. Paracetamol induced hepatic toxicity and amelioration by cinnamon in rats. Int $\mathrm{J}$ Pharmacol and Toxicol. 2016; 4 (2): 187-190. doi: 10.14419/ijpt.v4i2.6529.

9-Baiomy AA, Attia HF, Soliman MM and Makrum 0 . Protective effect of ginger and zinc chloride mixture on the liver and kidney alterations induced by Malathion toxicity. Int J Immunopathol Pharmacol 2015; 28(1) 122- 128. doi: 10.1177/0394632015572083.

10-Asadi E, Naderi M, Akbari MR, Khaksar K, Khajali F. Effects of dietary inclusion of turmeric (curcuma longa) and cinnamon (cinnamomum verum) powders on performance, organs relative weight and some immune system parameters in broiler chickens. Poultry Science Journal, 2014; 2:153-163. doi: 10.22069/psj.2014.1963.

11-Al-Jamal A, Rasheed IN. Effects of cinnamon (Cassia zelynicum) on diabetic rats. African J. of Food Sci. 2010; 4 (9): 615-617. Available at: http://www. academicjournals.org/ajfs

12-Shermer S. Rats haemopiotic system. In: the blood morphology of laboratory animals. 1968; Chap. 2: 4243. Pbl. F.A. Davis Co., Philadelphia U.S.A

13-Reitman S, Frankel S. A colorimetric method for the determination of serum glutamic oxalacetic and glutamic pyruvic transaminases. Am J Clin Pathol., 1957; 28 (1): 56-63. doi: 10.1093/ajcp/28.1.56.

14-Chaney A, Marbach E. Modified reagents for determination of urea and ammonia. Clin Chem. 1962; 8:130-132. doi.org/10.1093/clinchem/8.2.130.

15-Dunicz BL. Simple and accurate method for the determination of creatine and creatinine. Clinica. Chimica. Acta. 1964; 9 (3): 203-209. doi.10.1016/00098981(64)90095-6.

16-Richter HJ, Lapointe YS. A Simple Method for the Determination of Blood Urea Nitrogen, with Special Reference to Automatic Colorimetric Analysis, Clinical Chemistry, 1959; 5 (6): 617-620 doi: 10.1093/ clinchem/5.6.617].

17-Allain CC, Poon LS, Chan CS, Richmond W, Fu PC Enzymatic determination of total serum cholesterol. Clin Chem. 1974; 20: 470-475. PMID: 4818200.

18-Fossati P, Prencipe L. Serum triglycerides determined calorimetrically with an enzyme that produces hydrogen peroxide. Clin Chem J 1998; 28(10): 2077-2080. PMID: 6812986.

19-Erdelmeier I, Gérard-Monnier D, Yadan JC, Chaudière J. Reactions of $\mathrm{N}$-methyl-2-phenylindole with malondialdehyde and 4-hydroxyalkenals. Mechanistic aspects of the colorimetric assay of lipid peroxidation. Chem Res Toxicol., 1998; 11(10):1184-94 doi: 10.1021/tx9701790. 
20-Aggarwal BB, Natarajan K. Tumor necrosis factors: developments during the last decade. Eur Cytokine Netw. 1996; 7(2):93-124. PMID: 2169060.

21-Weydert CJ, Cullen JJ. Measurement of superoxide dismutase, catalase and glutathione peroxidase in cultured cells and tissue. Nat Protoc. 2010; 5(1): 51-66 doi: 10.1038/nprot.2009.197.

22-Mannervik B, Alin P, Guthenberg C, Jensson H, Warholm $M$. Identification of three classes of cytosolic glutathione transferase common to several mammalian species: correlation between structural data and enzymatic properties. Proc Natl Acad Sci USA. 1985; 82 (21): 7202-7206. doi: 10.1073/pnas 82.21.7202.

23-Ozyurt D, Demirata B, Apak R. Determination of Total Antioxidant Capacity by a New Spectrophotometric Method Based on Ce(IV) Reducing Capacity Measurement. Talanta. 2007; 71(3): 1155-65. doi: 10. 1016/j.talanta. 2006.06.015.

24-Elhelaly AE, AlBasher G, Alfarraj S, Almeer R, Bahbah E, Fouda $M$, et al. Protective effects of hesperidin and diosmin against acrylamide-induced liver, kidney, and brain oxidative damage in rats. Environmen Sci Pollution Res. 2019; 10 (19): 1-9. Doi:10.1007/s11356-01906660-3.

25-Hammad AY, Osman ME, Abdelgadir WS. Effects of acrylamide toxicity on growth performance and serobiochemistry of Wistar rats. Br J Pharmacol Toxicol 2013; 4 (13) 163-168. doi:10.19026/bjpt.4.5396

26-Singh MP, Jakhar R and Kang SK. Morin hydrate attenuates the acrylamide-induced imbalance in antioxidant enzymes in a murine model. International Journal of Molecular Medicine, 2015; 36: 992-1000. doi: 10.3892/ijmm.2015.2306.

27-Hamdy SM, Shabaan AM, Abdel Latif AK, Abdel-Aziz AM, Amin AM. Protective effect of hesperidin and Tiger nut against acrylamide toxicity in female rats. Exp Toxicol Pathol. 2017; 69:580-588. doi: 10.1016/j.etp. 2017. 05. 004.

28-Belhadj Benziane A, Dilmi Bouras A., Mezaini A., Belhadri A., Benali M. Effect of oral exposure to acrylamide on biochemical and hematologic parameters in Wistar rats. Drugs Chem Toxicol. 2018; 1: 157-166. Doi: 10.1080/ 01480545.2018].

29-Ghorbel I, Maktouf S, Fendri N, Jamoussi K, Ellouze S, Zeghal N. Co-exposure to aluminum and acrylamide disturbs expression of metallothionein, proinflammatory cytokines and induces genotoxicity: biochemical and histopathological changes in the kidney of adults rats. Environ Toxicol. 2016; 9 (16) 1044-1058. doi: 10.1002/t ox.22114.

30-Abdel-Daim MM, Abd Eldaim MA, Hassan AG. Trigonella foenum-graecum ameliorates acrylamide-induced toxicity in rats: roles of oxidative stress, proinflammatory cytokines, andDNA damage. Biochem Cell Biol. 2015; 93:192-198. doi: 10.1139/bcb-2014-0122.

31-Ghorbel I, Elwej A, Fendri N. Olive oil abrogates acrylamide induced nephrotoxicity by modulating biochemical and histological changes in rats. Ren Fail. 2017; 39(1):236-245 doi: 10.1080/0886022X.2016. 1256320.

32-Akram S, Amin K, Sulaiman Rahman H, Hassan O. The pathophysiological effects of acrylamide in Albino Wister rats. Int J Med Res Health Sci. 2016; 5 (7): 42-48.

33-Ismail NF, Ghareeb DA, Hafez EE, EL-Saadani MA, ElSayed MM, El Sewedy TS. Protective Effect of Cinnamon Zeylanicum, Berberis Vulgaris and Ulva Lactuca Extracts on Hepatocellular Toxicity Induced by Aspergillus Flavus Intake in Rats. Bull Egypt Soc Physiol Sci. 2017; 38(2), 111- 122. doi: 10.21608/besps. 2018. 8158.

34-Shalaby MA, Saifan HY. Some pharmacological effects of cinnamon and ginger herbs in obese diabetic rats $\mathrm{J}$ Intercult Ethnopharmacol. 2014; 3(4): 144-149 doi: 10. 5455/jice.20140818050741.

35-Abd El Fadil H, Moustafa A, Khalifa H, Hossam A, Behairy A. Cinnamon Extract Ameliorates Liver Damage And Oxidative Stress Induced By Paracetamol In Male Rats. Damanhour Journal of Veterinary Sciences, 2020; 3 (2): 14-20. doi: 10.5455/djvs.2020.25744.1011.

36-Hamza ZR, Al-Harbi MS. Amelioration of paracetamol hepatotoxicity and oxidative stress on mice liver with silymarin and extract supplements. Asian Pacific J Trop Biomed. 2015; 5(7): 521-31. doi: 10.1016/j.apjtb. 2015. 03.011.

37-Kassaee SM, Goodarzi MT, Roodbari NH, Yaghmaei P. The Effects of Cinnamomum zeylanicum on Lipid Profiles and Histology Via Up-Regulation of LDL Receptor Gene Expression in Hamsters Fed a High Cholesterol Diet. Jundishapur J Natural Pharmaceut Prod. 2017; 12(3): 37340. doi: 10.5812/jjnpp.37340.

38-Khare $P$, Jagtap $S$, Jain $Y$, Bishnoi M. Cinnamaldehyde supplementation prevents fasting-induced hyperphagia, lipid accumulation and inflammation in high-fat diet-fed mice. Article Bio Factors. 2016; 42: 77-82. doi: 10.1002/ biof.1265.

39-Khandouzi N, Shidfar F, Rajabc A, Rahidehd T, Hosseini $P$, Taheri MM. The effects of ginger on fasting blood sugar, hemoglobin A1c, apolipoprotein b, apolipoprotein a-i and malondialdehyde in type-2 diabetic patients. IJPR. 2015; 14 (1): 131-140 [PMCID:PMC4277626].

40-Alshathly MR. Efficacy of Ginger (Zingiber officinale) in ameliorating streptozotocin-induced diabetic liver injury in rats: Histological and biochemical studies. J Microsc Ultrastruct 2019; 7:91-101. doi: 10.4103/ JMAU. JMAU _16_19. 
41-Attyah AM, Ismail SH. Protective Effect of Ginger Extract Against Cisplatin-Induced Hepatotoxicity and Cardiotoxicity in Rats. Iraqi J Pharm Sci, 2012; 21(1): 27-33.

42-Shatwan IA, Ahmed LA, Badkook MM. Effect of barley flour, crude cinnamon, and their combination on glycemia, dyslipidemia, and adipose tissue hormones in type 2 diabetic rats. J Med Food, 2013; 16:656-62. doi: 10.1089/jmf.2012.0083.

43-Mani V, Siddique Al, Arivalagan S, Thomas NS, Namasivayam N. Zingerone ameliorates hepatic and renal damage in alcohol-induced toxicity in experimental rats. Int J Nutr Pharmacol Neurol Dis. 2016; 6:125-32. doi: 10.4103/2231-0738.184585.

44-Shanmugam KR, Ramakrishna CH, Mallikarjuna K, Reddy KS. Protective effect of ginger against alcohol-induced renal damage and antioxidant enzymes in male albino rats. Indian J Exp Biol. 2010; 48:143-9. PMID: 20455323.

45-Qin B, Polansky M, Sato Y, Adeli K, Anderson R. Cinnamon extract inhibits the postprandial overproduction of apolipoprotein B48-containing lipoproteins in fructose-fed animals. J Nutr Biochem. 2009; 20(11): 901-908 doi: 10.1016/j.jnutbio. 2008. 08.005.

46-Gholamreza D, Mehrnoosh S, Afshar J, Mustafa M, Reza B. Effect of endurance training and cinnamon supplementation on post-exercise oxidative responses in rats Mol Biol Res Commun. 2014; 3(4): 269-281. PMCID: PMC5019312.
47-Morgan AM, El-Ballal SS, El-Bialy BE, EL-Boraic N. Studies on the potential protective effect of cinnamon against bisphenol $\mathrm{A}$ - and octylphenol-induced oxidative stress in male albino rats. Toxicol Reports 2014; 1 (14): 92-101. DOI: 10.1016/j.toxrep.2014.04.003

48-Sathya M, Rajeshwari V, Sakthishree K. Influence of aqueous extract of Cinnamomum zeylanicum on the progression of cancer in diethylnitrosamine induced rat liver. Eur J Experimen Biol. 2014; 4: 190- 195.

49-Alireza O, Sepide M, Majid M, Ebrahimzade VA, Laleh P. anti-inflammatory effects of Zingiber officinale in type 2 diabetic patients. Adv Pharmaceut Bull. 2013; 3:273276. doi: 10.5681/apb.2013.044.

50-Zhang G, Yang Z, Wang Y, Yang W, Jiang S, Gai G. Effects of ginger root (Zingiber officinale) processed to different particle sizes on growth performance, antioxidant status, and serum metabolites of broiler chickens. Poult. Sci. 2009; 88(10): 2159-2166. doi: 10.3382/ps.2009-00165.

51-Sadeghi A, Moghaddam M. The Effects of Turmeric, Cinnamon, Ginger and Garlic Powder Nutrition on Antioxidant Enzymes' Status and Hormones Involved in Energy Metabolism of Broilers during Heat Stress. Iran J Applied Animal Sci. 2018; 8(1): 125-130. doi: . 


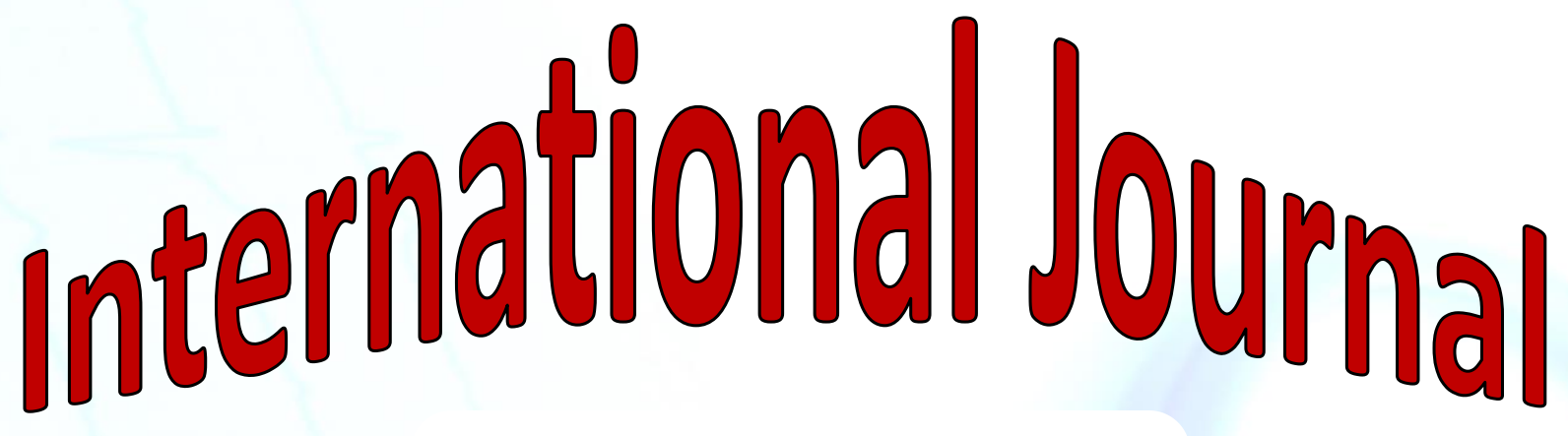

https://ijma.journals.ekb.eg/

Print ISSN: 2636-4174

Online ISSN: 2682-3780

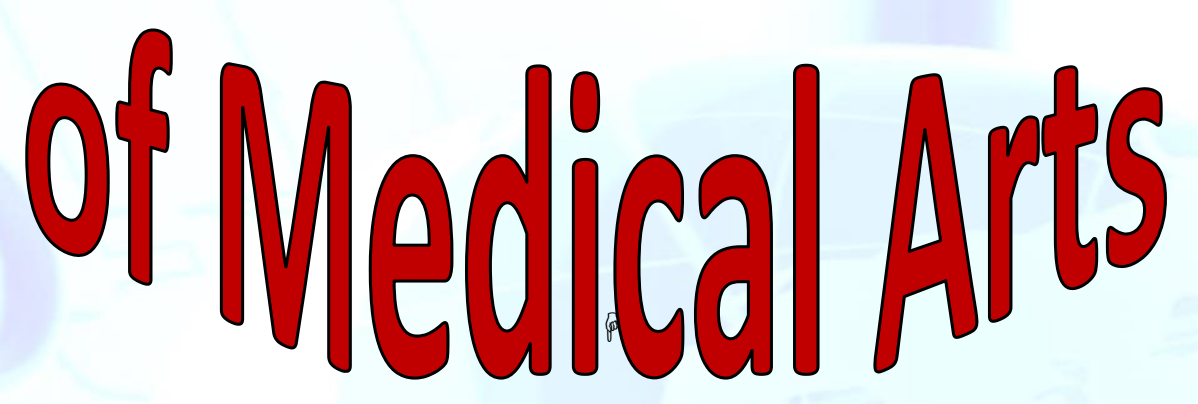

